RESEARCH ARTICLE

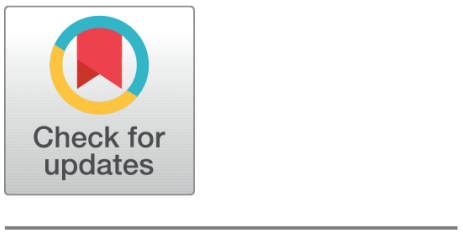

OPEN ACCESS

Received: 20.07.2021

Accepted: 28.07.2021

Published: 24.08 .2021

Citation: Anjan Babu VA, Saravanan R, Raviprakash $\mathrm{M}$, Nagaral M (2021) Microstructure, Tensile and Flexural Strength of Boron Carbide Particles Reinforced Al2030 Alloy Composites. Indian Journal of Science and Technology 14(28): 2342-2350. https://doi.org/ 10.17485/IJST/v14i28.1341

Corresponding author.

va.anjan@gmail.com

Funding: None

Competing Interests: None

Copyright: (c) 2021 Anjan Babu et al. This is an open access article distributed under the terms of the Creative Commons Attribution License, which permits unrestricted use, distribution, and reproduction in any medium, provided the original author and source are credited.

Published By Indian Society for Education and Environment (iSee)

ISSN

Print: 0974-6846

Electronic: 0974-5645

\section{Microstructure, Tensile and Flexural Strength of Boron Carbide Particles Reinforced Al2030 Alloy Composites}

\author{
V A Anjan Babu ${ }^{1,2 *}$, R Saravanan ${ }^{3}$, M Raviprakash ${ }^{4}$, Madeva Nagaral ${ }^{5}$ \\ 1 Research Scholar, Department of Mechanical Engineering, UVCE, Bangalore, 560001 \\ 2 Assistant Professor, Department of Mechanical Engineering, East Point College of \\ Engineering \& Technology, Bangalore, 560083 \\ 3 Associate Professor, Department of Mechanical Engineering, UVCE, Bangalore, 560001 \\ 4 Associate Professor, Department of Mechanical Engineering, The Oxford College of \\ Engineering, Bangalore, 560068 \\ 5 Deputy Manager, Aircraft Research and Design Centre, HAL, Bangalore, 560037
}

\section{Abstract}

Objective: To synthesize and assess the mechanical behaviour of $12 \mathrm{wt} . \%$ of 80 to 90 micron sized $\mathrm{B}_{4} \mathrm{C}$ reinforced Al2030 alloy metal composites. Method: Al2030 alloy with 12 wt. \% of $B_{4} C$ reinforced composites were developed by liquid melt stir cast method. These prepared composites were subjected to microstructural characterization by SEM, EDS and XRD. Mechanical properties like hardness, tensile and flexural strength were evaluated according to ASTM standards. Findings: Scanning electron micrograph of Al2030 alloy with 12 wt. $\%$ of $\mathrm{B}_{4} \mathrm{C}$ composites revealed the thorough distribution of boron carbide particles in the Al2030 matrix. EDS and X-ray diffractometer patterns confirmed the presence of boron carbide particles in the Al2030 alloy matrix. The addition of $12 \mathrm{wt}$. \% of $\mathrm{B}_{4} \mathrm{C}$ particles enhanced the hardness by $74.8 \%$, ultimate strength by $59.2 \%$, yield strength by $64.8 \%$ and flexural strength by $44.2 \%$ with slight decrease in ductility. Novelty: Al2030 alloy is an aerospace grade aluminium alloy widely used for industrial applications. Advanced metal composites developed with the incorporation of 80 to 90 micron sized $\mathrm{B}_{4} \mathrm{C}$ particles in Al2030 alloy helps in weight reduction of aerospace components.

Keywords: Al2030 Alloy; B 4 C Particles; Microstructure; Tensile Strength; Flexural Strength; Fractography

\section{Introduction}

There is a never-ending demand for new and advanced composite materials due to their lightweight and outstanding mechanical properties. Notably many industries are profitable and society is getting benefit from stronger, lighter and cost- effective materials ${ }^{(1,2)}$. From household appliances to nuclear industry composites are popular, especially in aerospace and military industries where weight is a key factor ${ }^{(3,4)}$. Composite materials are the field of interest for many scholars all over the world, as they are an essential part of latest trending technology. 
$\mathrm{Gu}$ Wan-li ${ }^{(5)}$ and co-authors were used micro and nano based $\mathrm{SiC}$ particles as reinforcement and introduced in $\mathrm{Al}$ homogenously for the preparation of nano-composites by ball milling them and later hot pressed. The microstructural studies of prepared nano composite were analysed by TEM along with studying the effect of $\mathrm{SiC}$ particulates. The results concluded that nano $\mathrm{SiC}$ particles were homogenously spread in $\mathrm{Al}$ by doing ball milling for 2 hours only, whereas for micro SiC needs 10 hours and agglomerated under same conditions.

Umashankar et al., ${ }^{(6)}$ and team was made use of Al-Si alloys as matrix and carbon nano tubes as a reinforcement of different weight $\%$ composites using powder metallurgy process. The prepared specimens where investigated for vibration test to examine the ratio of damping and natural frequency under standard conditions. It was noted that considerable amount of improvement in damping ratio, natural frequency with $0.5 \mathrm{wt} \%$, but the stiffness decreased because of clustering for the same $0.5 \mathrm{wt} . \%$. Further increase of nano reinforcement above $0.5 \mathrm{wt}$. \% led to decline in the above properties as mentioned because of agglomeration and the same was experienced in TEM when characterized.

Kurahatti et al., ${ }^{(7)}$ and team make use of nano $\mathrm{ZrO}_{2}$ fillers as reinforcement which was incorporated in epoxy to evaluate the wear behaviour. To obtain uniform dispersion high shear mixing process was utilized. Low rate of friction coefficient and lesser wear rate were noted by usage of nano particles observed against the sliding steel disc. Mechanical properties such as Charpy test had a relationship with wear behaviour in increasing the property.

Production and characterization of the nano composites prepared by vortex stir casting with the help of nano alumina powder $\left(\mathrm{Al}_{2} \mathrm{O}_{3}\right)$ which was incorporated in $\mathrm{Al}$ alloy (A413) by R. Surendran ${ }^{(8)}$. The prepared nano composites were observed under scanning electron microscope for proper uniform distribution of particles. The mechanical properties like material hardness, impact and tensile strength was investigated and it was observed that due to addition of effect of nano $\mathrm{Al}_{2} \mathrm{O}_{3}$ the properties had been enhanced. The wear behaviour was tested under dry sliding condition on pin on disc machine and it was noticed that wear resistance increased due to increase in volume fraction of nano reinforcement and the wear morphology was inspected SEM.

$\mathrm{Al}$ nano composites was fabricated by friction stirring technique in which $\mathrm{TiO}_{2}$ nano particles is reinforced in $\mathrm{Al}-\mathrm{Mg}$ alloy with varying weight percentage and later annealed to know the impact of annealing on mechanical properties and microstructural changes by $\mathrm{F}$. Khodabakhshi ${ }^{(9)}$. By increasing volume of the nano particles, the hardness and yield strength increased but the UTS and elongation decreased considerably. It was also noted that reactive annealing completed without reducing the tensile property and hardness. Evaluation of the grain structure showed that during friction stir technique, the presence of titanium oxide nanoparticles refined the grains while forming the in situ shaped nanoparticles impeded grain growth after post-annealing treatment. Controlled annealing 3 hours at $400^{\circ} \mathrm{C}$ enhanced the maximum tensile strength and ductility of the nano-composites.

In this $\mathrm{B}_{4} \mathrm{C}$ particles with 80 to 90 micron size were combined into the Al2030 alloy to manufacture Al2030 - 12 wt. \% of $\mathrm{B}_{4} \mathrm{C}$ composites. These prepared composites were subjected to microstructural studies by SEM, EDS and XRD. Mechanical properties like hardness, tensile and flexural strength were evaluated according to ASTM standards.

\section{Experimental Details}

\subsection{Materials Used}

Metal composites with 12 wt. \% of $\mathrm{B}_{4} \mathrm{C}$ particulates with 80 to 90 micron size were delivered by stir process. Aluminum 2030 compound (Fenfee Metallurgical Pvt. Ltd., Bangalore) is an aerospace alloy with copper as a major element in $\mathrm{Al}$ matrix.

\begin{tabular}{ll}
\multicolumn{2}{l}{ Table 1. Chemistry of Al2030 alloy } \\
\hline Elements (wt. \%) & Al2030 (actual) \\
\hline $\mathrm{Zn}$ & 0.91 \\
$\mathrm{Mg}$ & 0.67 \\
$\mathrm{Si}$ & 0.21 \\
$\mathrm{Fe}$ & 0.23 \\
$\mathrm{Cu}$ & 0.07 \\
$\mathrm{Mn}$ & 0.02 \\
$\mathrm{~Pb}$ & 0.03 \\
$\mathrm{Mn}$ & 0.06 \\
$\mathrm{~Pb}$ & 0.03 \\
$\mathrm{Mn}$ & 0.06 \\
$\mathrm{Al}$ & Balance \\
\hline
\end{tabular}


Table 1 shows the synthetic arrangement of the Al2030 amalgam used in the current examinations.

$\mathrm{B}_{4} \mathrm{C}$ particles of 80-90 $\mu \mathrm{m}$ (Supplied by Speedfam Limited, Chennai, Tamilnadu, India) sized are utilized. Figure 1 (a-b) is SEM and EDS spectrum of boron carbide particles.

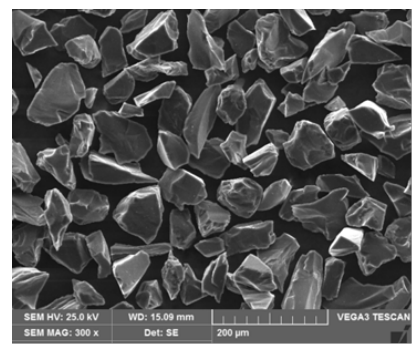

a

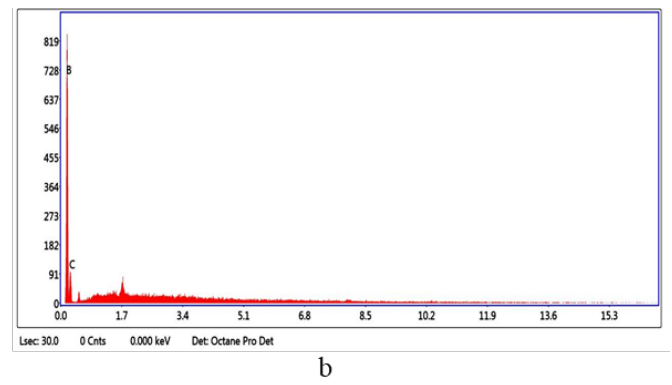

b

Fig 1. (a) $S E M$ micrograph of $B_{4} C$ (b) EDS spectrum of $B_{4} C$

\section{Preparation of Composites}

Al2030 alloy with 12 wt. $\%$ of $\mathrm{B}_{4} \mathrm{C}$ reinforced composites were developed by stir cast process. A known quantity of Al2030 alloy pieces were placed in a crucible made by graphite. Further, electrical resistance furnace was used to melt the Al2030 alloy. The temperature used for the preparation of metal composite was $750^{\circ} \mathrm{C}$. After complete melting of Al2030 alloy degassing was carried out by utilizing $\mathrm{C}_{2} \mathrm{Cl}_{6}$ tablets. This is usually done to remove the unwanted gases from the molten material. The preheated boron carbide particles added into the Al2030 alloy melt. During addition of these particles, the molten metal and $\mathrm{B}_{4} \mathrm{C}$ mixture was stirred at $300 \mathrm{rpm}$ using zirconia coated steel impeller. After complete additions of particles, the entire mixture was poured in a die. The prepared Al2030 alloy with 12 weight $\%$ of $\mathrm{B}_{4} \mathrm{C}$ composites were evaluated for various properties.

The size, shape and dissemination of $\mathrm{B}_{4} \mathrm{C}$ present in Al2030 composites are finished using SEM mechanical assembly. The machine was associated with JED 2300 assessment programming program for EDX examination. For SEM, specimens were sliced to get $15 \mathrm{~mm}$ in measurement and $5 \mathrm{~mm}$ stature. The cut samples were made level surface utilizing belt processor. Then, at that point the specimens were cleaned on a progression of silicon carbide emery papers with coarseness size of 300 to 1000 . Completing was done by hand on miniature material by fine cerium oxide. The prepared microstructural specimens were etched by using Keller's reagent. The scratching arrangement comprises of $95 \mathrm{ml}$ of $\mathrm{H}_{2} \mathrm{O}$, almost $2.5 \mathrm{ml} \mathrm{HNO}$, likewise $1.5 \mathrm{ml} \mathrm{HCl}$ and $1 \mathrm{ml} \mathrm{HF}$. In the wake of drawing, the examples are washed and altogether dried.

In current work the hardness of as cast Al2030 alloy and Al2030 alloy $12 \mathrm{wt} \%$ of $\mathrm{B}_{4} \mathrm{C}$ composites is evaluated using $5 \mathrm{~mm}$ ball indenter with load application of $250 \mathrm{kgf}$ and dwell time of 30 seconds for each sample at different locations have been conducted. Figure 2 indicates the samples used in the study.

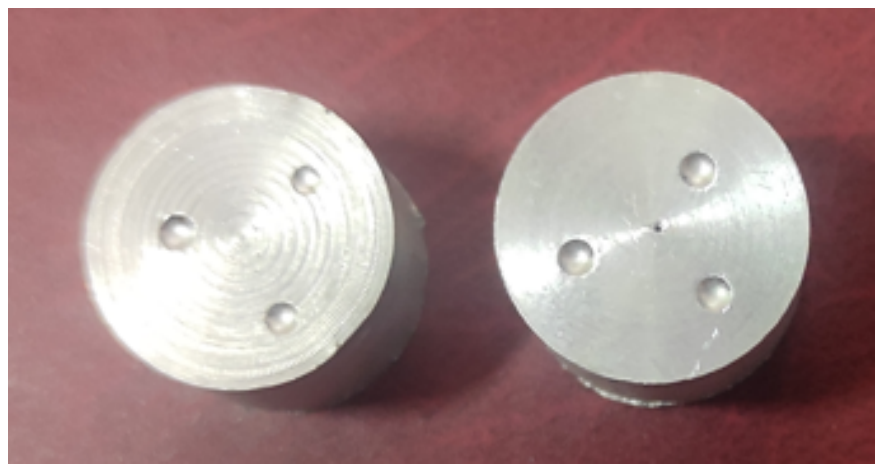

Fig 2. Hardness specimens

Tensile tests were conducted by using Instron made UTM machine having $60 \mathrm{kN}$ load capacity with $4 \mathrm{kN}$ least count. The tensile samples were having a component of $45 \mathrm{~mm}$ measure length according to ASTM E8 ${ }^{(10)}$ standard as in Figure 3 After the test, break surfaces are introduced for microstructural examines utilizing SEM to comprehend the crack system. 


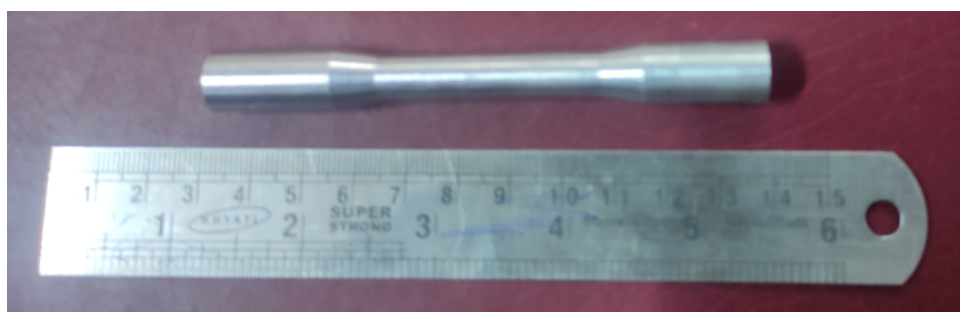

Fig 3. Tensile test specimen

ASTM E290 standard is used to evaluate the flexural strength of Al2030 alloy and its 12 weight of $\mathrm{B}_{4} \mathrm{C}$ reinforced composites. Figure 4 is showing the flexural test specimen.

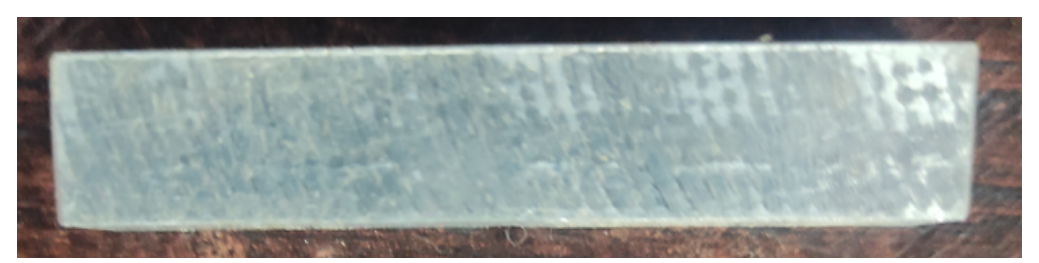

Fig 4. Sample of flexural test specimen

\section{Results and Discussion}

\subsection{Microstructural Studies}

Figure 5 (a-b) is the pictures of SEM for as cast Al2030 combination and Al2030 compound with 12 wt. \% of $\mathrm{B}_{4} \mathrm{C}$ composites. Figure 5(a) and (b) shows the SEM of Al2030 compound and Al2030 mixture with 12 weight paces of miniature $\mathrm{B}_{4} \mathrm{C}$ composites. Figure 5(a) addresses the micrograph of Al2030 combination with fine grains with no pores. Further, Figure 5(b) shows the presence of $\mathrm{B}_{4} \mathrm{C}$ in the Al2030 combination, there is a strong holding between the Al2030 matrix and $\mathrm{B}_{4} \mathrm{C}$ particles. The two phase support expansion strategy worked on the dissemination of particles in the Al2030 combination. Along these lines appropriated particles helps in working on the properties of the composites.

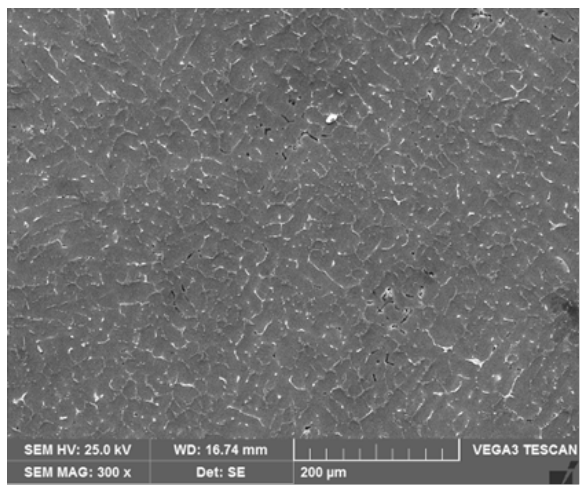

a

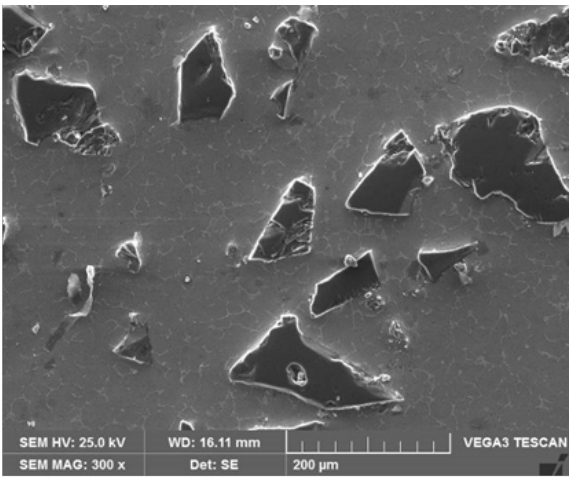

b

Fig 5. SEM of (a) Al2030 alloy (b) Al2030-12 wt. \% of $\mathrm{B}_{4} \mathrm{C}$ composites

Figure 6(a-b) is the EDS ranges of Al2030 combination and 12 wt. \% of $\mathrm{B}_{4} \mathrm{C}$ particulates composites. Figure 6(a) shows the alloying parts present in Al2030 compound, with $\mathrm{Cu}$ as main alloying segments with $\mathrm{Si}$ and $\mathrm{Mg}$. Figure 6(b) is the EDS investigation of $\mathrm{Al} 2030-12$ wt. \% of $\mathrm{B}_{4} \mathrm{C}$ composites, the range affirms the $\mathrm{B}_{4} \mathrm{C}$ particles as $\mathrm{B}$ and $\mathrm{C}$ components in the created composites. 

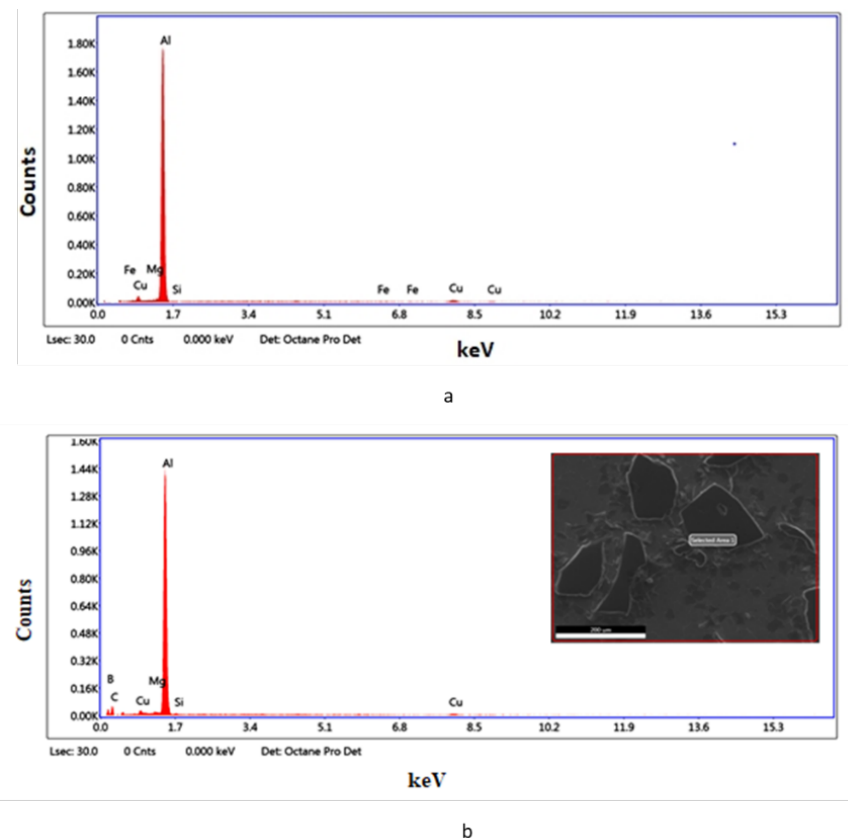

Fig 6. EDS spectrums of (a) Al2030 (b) Al2030-12 wt. \% of $\mathrm{B}_{4} \mathrm{C}$ composites

To analyze the existence of $\mathrm{Al}$ and $\mathrm{B}_{4} \mathrm{C}$ in the $\mathrm{Al} 2030-\mathrm{B}_{4} \mathrm{C}$ composites, the $\mathrm{XRD}$ examination is made. Figure $7(\mathrm{a})$ is the $\mathrm{XRD}$ sample of Al2030 composite which encompasses the $\mathrm{Al}$ stages at $39^{\circ}, 45^{\circ}, 65^{\circ}$ and $78^{\circ}$. Figure $7(\mathrm{~b})$ is the XRD example of $12 \mathrm{wt}$. $\%$ of $\mathrm{B}_{4} \mathrm{C}$ particles built up composites, which comprises $\mathrm{B}_{4} \mathrm{C}$ stages at $42^{\circ}, 52^{\circ}$ and $83^{\circ}$.
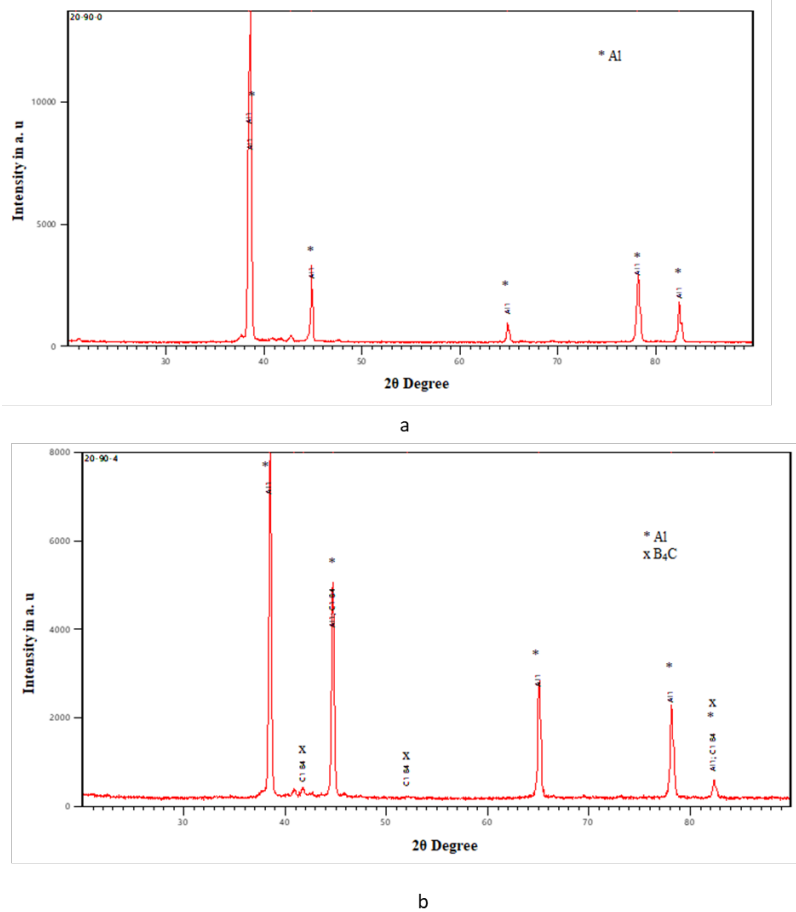

Fig 7. XRD patterns of (a) Al2030 alloy (b) Al2030-12 wt. \% of $\mathrm{B}_{4} \mathrm{C}$ composites 


\subsection{Hardness Measurements}

Figure 8 is hardness of Al2030 compound and Al2030 with 12 weight level of $\mathrm{B}_{4} \mathrm{C}$ composites. From Figure 8 indicates the impact of $\mathrm{B}_{4} \mathrm{C}$ particles on the hardness of $\mathrm{Al} 2030$ compound. The hardness assessment of base material cast $\mathrm{Al} 2030 \mathrm{blend}$ is 65.5 $\mathrm{BHN}$, after the addition of $\mathrm{B}_{4} \mathrm{C}$ particulates by using two step novel stir cast method, there is an increment in hardness from $65.5 \mathrm{BHN}$ to $114.5 \mathrm{BHN}$. There is an increment of $74.8 \%$ hardness for Al2030-12 wt. \% of $\mathrm{B}_{4} \mathrm{C}$ composites. The progress in hardness of $\mathrm{Al} 2030$ is a direct result of the existence of hard particles $\mathrm{B}_{4} \mathrm{C}$ in the soft matrix. The hardness extended in the sensitive structure as the hardness of $\mathrm{B}_{4} \mathrm{C}$ particles is $2700 \mathrm{BHN}$, which fabricates the hardness of $\mathrm{Al} 2030-\mathrm{B}_{4} \mathrm{C}$ lattice. Balaraj and co-authors investigated the effect of $\mathrm{Al}_{2} \mathrm{O}_{3}$ particles on hardness of Al6061 alloy ${ }^{(11)}$.

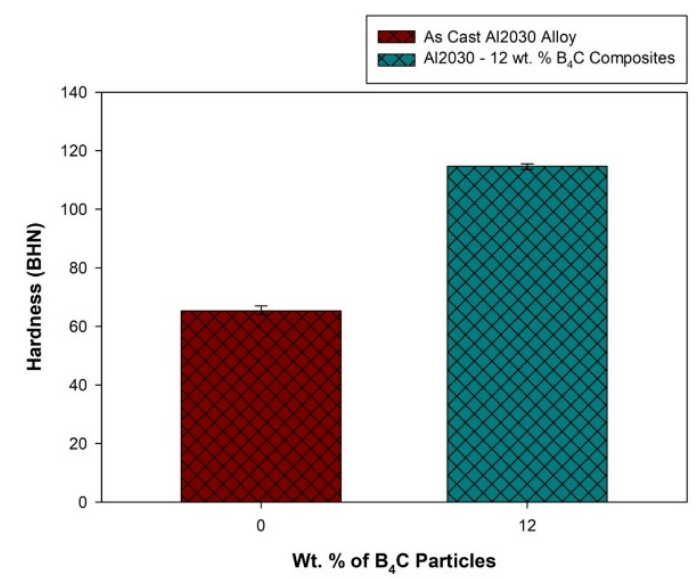

Fig 8. Hardness of $\mathrm{Al} 2030$ alloy and $\mathrm{B}_{4} \mathrm{C}$ composites

\subsection{Ultimate Tensile and Yield Strength}

Figure 9 shows a definitive strength by the effect of $\mathrm{B}_{4} \mathrm{C}$ on $\mathrm{Al} 2030$ mixture. The UTS assessment of base material cast $\mathrm{Al} 2030$ mix is $206 \mathrm{MPa}$, after the extension of $\mathrm{B}_{4} \mathrm{C}$ particulates by two step cast technique there is an increase in UTS from $206 \mathrm{MPa}$ to $327.9 \mathrm{MPa}$. There is an enhancement of $59.2 \%$ strength for Al2030-12 wt. \% of $\mathrm{B}_{4} \mathrm{C}$ composites. The SEM micrographs obviously showed the solid interfacial holding of $\mathrm{Al} 2030$ network and $\mathrm{B}_{4} \mathrm{C}$; this holding assists with moving the pivotal elastic load from grid to the $\mathrm{B}_{4} \mathrm{C}^{(12)}$. This hard molecule keeps away from the plastic progression of Al grid and subsequently upgrades the load carrying limit of Al2030 matrix. Pankaj et al. ${ }^{(13)}$ investigated the effect of boron carbide content on the properties of A356 alloy; the addition of $\mathrm{B}_{4} \mathrm{C}$ particles improved the tensile strength of A356 alloy.

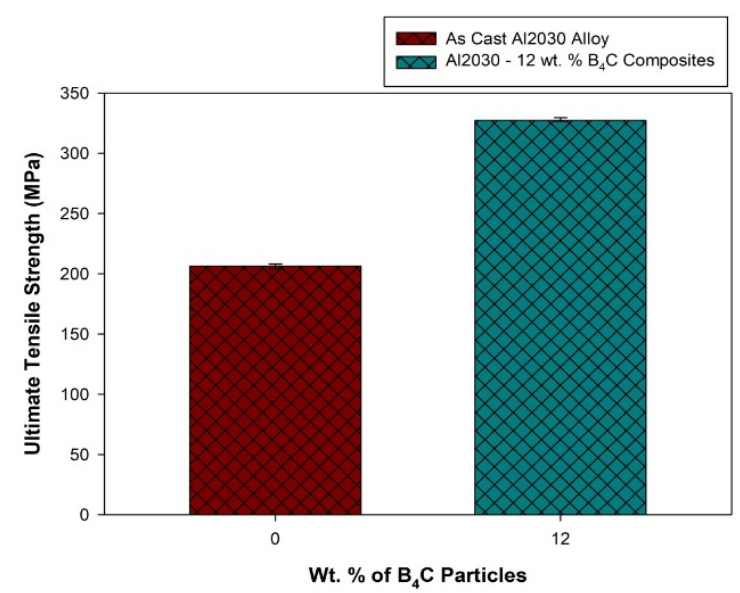

Fig 9. Ultimate tensile strength of Al2030 alloy and $\mathrm{B}_{4} \mathrm{C}$ composites 


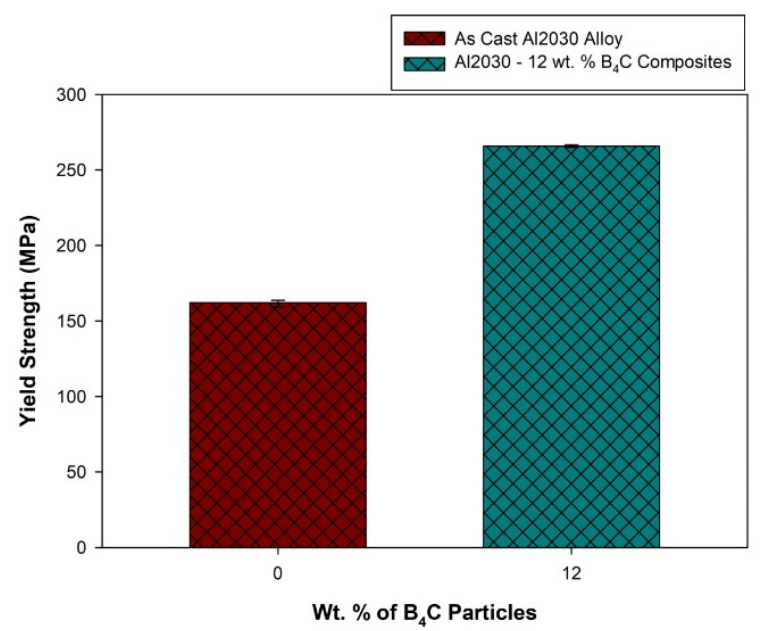

Fig 10. Yield strength of Al2030 alloy and $\mathrm{B}_{4} \mathrm{C}$ composites

Figure 10 is the plot of yield strength of Al2030 combination and Al2030 compound with 12 wt. \% of $\mathrm{B}_{4} \mathrm{C}$ composites. The yield strength of Al2030 combination is $161.4 \mathrm{MPa}$, an improvement is seen after the adding of $12 \mathrm{wt} \%$ of $\mathrm{B}_{4} \mathrm{C}$ in the $\mathrm{Al}$ network. The strength of Al2030 with 12 wt. \% $\mathrm{B}_{4} \mathrm{C}$ composites is $265.9 \mathrm{MPa}$. These hard particles are causative in the yield strength improvement by $64.7 \%$. The SEM micrographs plainly demonstrated the solid interfacial holding of Al2030 network and $\mathrm{B}_{4} \mathrm{C}$ particles; this strong bonding helps to move load from matrix to reinforcements. This hard molecule dodges the plastic progression of $\mathrm{Al}$ network and accordingly improves the load conveying limit of Al2030 matrix.

\subsection{Percentage Elongation}

Figure 11 portrays the decrements in the rate stretching of the delivered composite by adding the $12 \mathrm{wt}$. $\%$ of $\mathrm{B}_{4} \mathrm{C}$ when stood out from the cast Al2030 lattice compound. The abatement in flexibility is a result of the accompanying reasons (I) void nucleation by expanding expansion level of support. The particular clarification for this distinction might be that $\mathrm{B}_{4} \mathrm{C}$ molecule acts like a pressure concentrator ii) the strong interfacial strength with support and network is incredibly high, prompting more prominent support load, along these lines cracking at lower strains ${ }^{(13,14)}$.

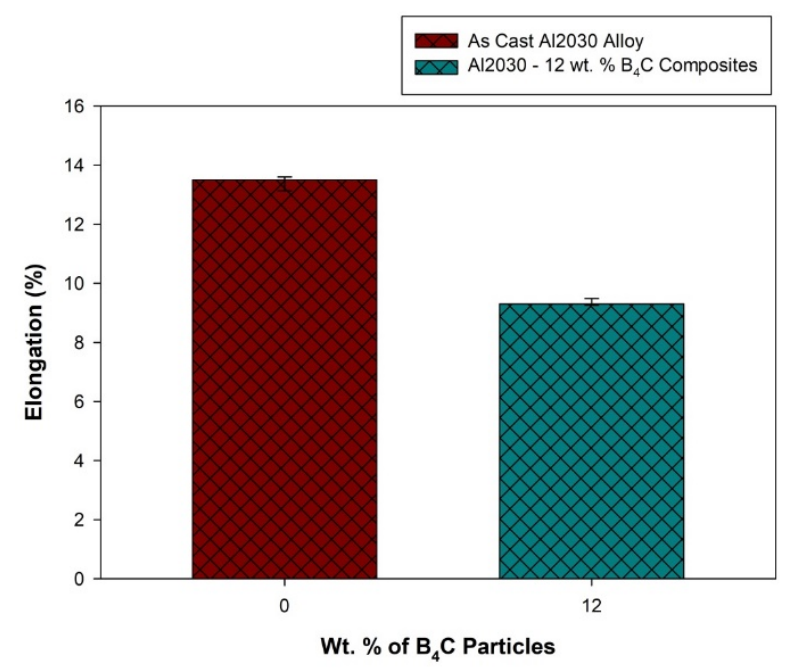

Fig 11. Percentage Elongation of $\mathrm{Al} 2030$ alloy and $\mathrm{B}_{4} \mathrm{C}$ composites 


\subsection{Flexural Strength}

Figure 12 is showing the effect strength of Al2030 alloy and its $12 \mathrm{wt}$. \% of $\mathrm{B}_{4} \mathrm{C}$ particles supported metal composites. The flexural strength of as-cast Al2030 matrix is $113.3 \mathrm{MPa}$, the expansion of carbide particles worked on the flexural solidarity to $163.4 \mathrm{MPa}$ on account of $\mathrm{Al} 2030-12 \mathrm{wt}$ \% $\mathrm{B}_{4} \mathrm{C}$ composites. The strong holding between the molecule and lattice interface made composites to assimilate more energy when contrasted with the as-projected Al grid. Improvement of the spotless interface between the lattice and support depends on the exchange of load consequently it assumes a critical part in expanding the composite strength. The presence of hard ceramic particles, a disengagement inadequacy happens, prompting stack up of separations accordingly further developed effect strength is produced.

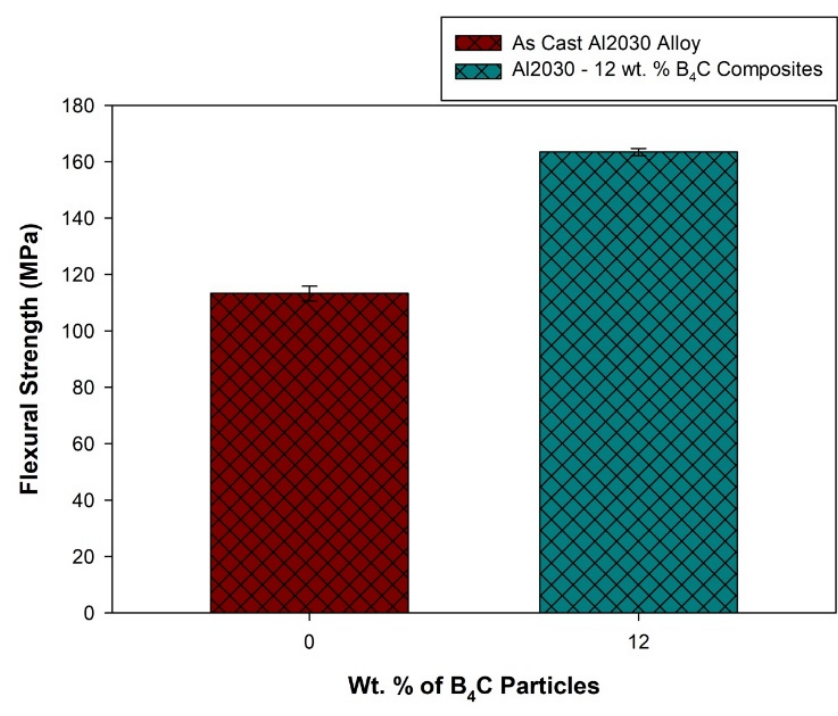

Fig 12. Flexural strength of $\mathrm{Al} 2030$ alloy and $\mathrm{B}_{4} \mathrm{C}$ composites

\subsection{Fracture Studies}

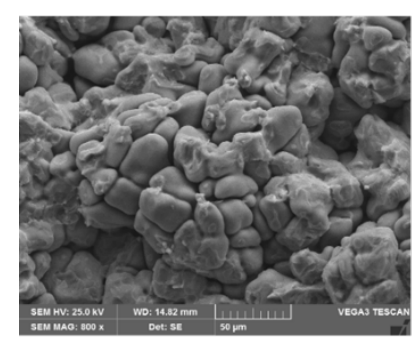

a

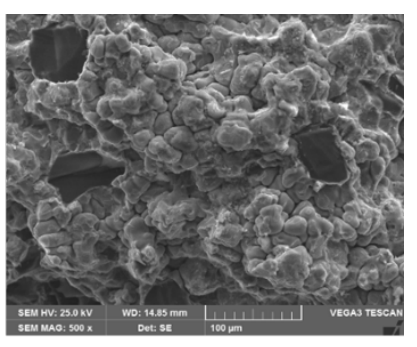

b

Fig 13. Fractured surfaces SEM micrographs of (a) Al2030 alloy (b) Al2030 - 12 wt. \% $\mathrm{B}_{4} \mathrm{C}$ composites

Figure $13 \mathrm{a}-\mathrm{b}$ is representing the tensile fractured surfaces SEM images of Al2030 alloy and $\mathrm{Al} 2030$ alloy with 12 wt. \% of $\mathrm{B}_{4} \mathrm{C}$ composites. Figure 13(a) is exhibiting ductile mode of fracture without any reinforcement. Brittle fracture mode is observed in 12 wt. $\%$ of $\mathrm{B}_{4} \mathrm{C}$ composites.

\section{Conclusions}

In the current work $\mathrm{Al} 2030-\mathrm{B}_{4} \mathrm{C}$ composites were effectively fabricated by using two stage novel stir cast process with 12 weight percentages boron carbide particles of 80 to 90 microns size. ASTM standards were utilised to investigate the various mechanical properties like hardness, UTS and YS, ductility, flexural strength and fractography conduct. As cast-combination and similarly 
appropriated miniature $\mathrm{B}_{4} \mathrm{C}$ composite, the network was essentially free from pores, as in SEM micrographs. The EDS and XRD investigation demonstrates that the $\mathrm{Al} 2030$ combination network incorporates $\mathrm{B}_{4} \mathrm{C}$ particles. The properties of Al2030 and 12 wt. $\% \mathrm{~B}_{4} \mathrm{C}$ composites were predominant when contrasted and unreinforced $\mathrm{Al} 2030$ as-projected amalgam. The crack surface of the combined composites contains small voids inferable from strain limitation. In the current work $12 \mathrm{wt}$. $\%$ of $\mathrm{B}_{4} \mathrm{C}$ particles utilized to develop composites, further to know the impact of higher weight percentages of particles addition on mechanical behaviour of Al2030 alloy can be studied.

\section{References}

1) Siddesh MS, Shivakumar BP, Shashidhar S, Nagaral M. Dry sliding wear behavior of mica, fly ash and red mud particles reinforced Al7075 alloy hybrid metal matrix composites. Indian Journal of Science and Technology. 2021;14(4):310-318.

2) Madeva N, Deshapande RG, Auradi V, Babu BS, Samuel D, Anilkumar MR. Mechanical and Wear Characterization of Ceramic Boron CarbideReinforced Al2024 Alloy Metal Composites. Journal of Bio- and Tribo-Corrosion. 2021;7(1):1-12. Available from: https://doi.org/10.1007/s40735-020-00454-8.

3) Lee D, Kim J, Lee SK, Kim Y, Lee SB, Cho S. Effect of Boron Carbide Addition on Wear Resistance of Aluminum Matrix Composites Fabricated by Stir Casting and Hot Rolling Processes. Metals. 2021;11:989-989. Available from: https://doi.org/10.3390/met1 1060989.

4) Kareem A, Qudeiri JA, Abdudeen A, Ahammed T, Ziout A. Review on AA 6061 Metal Matrix Composites Produced by Stir Casting. Materials. 2021;14(1). Available from: https://doi.org/10.3390/ma14010175.

5) Wan-Li G. Bulk Al/SiC nanocomposite prepared by ball milling and hot-pressing method. Transactions of Nonferrous Metals Society of China. 2006;16(1):398-401. Available from: https://doi.org/10.1016/S1003-6326(06)60219-7.

6) Umashankar KS, Gangadharan KV, Desai V, Shivamurthy B. Fabrication and Investigation of Damping Properties of Nano Particulate Composites. Journal of Minerals \& Materials Characterization \& Engineering. 2010;9:819-830. Available from: 10.4236/jmmce.2010.99059.

7) Kurahattia RV, Surendranathan AO, Kumar AVR, Wadageri CS, Kori SAA. Dry Sliding Wear behaviour of Epoxy reinforced with nano ZrO2 Particles. Procedia Materials Science. 2014;5:274-280. Available from: https://doi.org/10.1016/j.mspro.2014.07.267.

8) Surendran R, A K. Study on Mechanical Properties and Wear Behaviour of LM6 Aluminum/ Nano Al2O3 Composites. Applied Mechanics and Materials. 2014;592-594:1352-1356. Available from: https://doi.org/10.4028/www.scientific.net/AMM.592-594.1352.

9) Khodabakhshi F, Simchi A, Kokabi AH, Gerlich AP, Nosko M. Effects of post annealing on the microstructure and mechanical properties of friction stir processed Al-Mg-TiO2 nanocomposites. Materials and Design. 2014;63:30-41. Available from: 10.1016/j.matdes.2014.05.065.

10) Bharath V, Auradi V, Nagaral M. Fractographic characterization of Al2O3p particulates reinforced Al2014 alloy composites subjected to tensile loading. Frattura ed Integrità Strutturale. 2021;15(57):14-23. Available from: http://www.esis-ph.eu/index.php/fis/article/view/2980.

11) Balaraj V, Kori N, Nagaral M, Auradi V. Microstructural evolution and mechanical characterization of micro Al2O3 particles reinforced Al6061 alloy metal composites. Materials Today Proceedings. 2021. Available from: https://doi.org/10.1016/j.matpr.2021.04.500.

12) Kumar HV, Kempaiah UN, Nagaral M, Revanna K. Investigations on Mechanical Behaviour of Micro B4C Particles Reinforced Al6061 Alloy Metal Composites. Indian Journal of Science and Technology. 2021;14(22):1855-1863. Available from: 10.17485/IJST/v14i22.736.

13) Jadhav PR, Sridhar BR, Nagaral M, Harti JI. Evaluation of mechanical properties of B4C and graphite particulates reinforced A356 alloy hybrid composites. Materials Today: Proceedings. 2017;4(9):9972-9976. Available from: https://doi.org/10.1016/j.matpr.2017.06.304.

14) Dama K, Prashanth L, Nagaral M, Mathapati R, Hanumantharayagouda MB. Microstructure and mechanical behaviour of B4C particulates reinforced ZA27 alloy composites. Materials Today Proceedings. 2017;4(8):7546-7553. Available from: https://doi.org/10.1016/j.matpr.2017.07.086. 